\title{
Special Issue of Papers by Plenary and Topical Invited Lecturers at the 22nd International Symposium on Plasma Chemistry (ISPC 22), 5-10 July 2015, Antwerp, Belgium: Introduction
}

\author{
Annemie Bogaerts ${ }^{1} \cdot$ Richard van de Sanden $^{2}$
}

Published online: 11 January 2016

(C) Springer Science+Business Media New York 2016

The ISPC 22 was organised jointly by the University of Antwerp and the Dutch Institute for Fundamental Energy Research from July 5 till July 10, 2015, in the beautiful town of Antwerp at the city campus of the University of Antwerp. The conference, whose governing body is the International Plasma Chemistry Society, spans the full range of plasma chemistry and plasma processing research, from fundamentals to applications, both from academia as well as from industry. The programme included contributions from lowpressure, atmospheric-pressure non-equilibrium and thermal plasmas. Furthermore, the conference was preceded by an industrial workshop on "Re-use of $\mathrm{CO}_{2}$ ", which took place on Sunday July $5^{\text {th }}$ at the University of Antwerp, as well as by an ISPC Summer school, which was hosted by DIFFER at its brand new location at the TU/e Science campus. In addition, the conference hosted the workshop on "Plasma-mediated effects on biological systems". This special issue, which we happily present, contains the papers by the plenary and topical invited lecturers of ISPC 22.

The 22nd International Symposium on Plasma Chemistry was chaired by Prof. dr. Annemie Bogaerts of the University of Antwerp and Prof. dr. ir. Richard van de Sanden from DIFFER and Eindhoven University of Technology. The conference was sponsored by the University of Antwerp, DIFFER, Fund for Scientific Research Flanders and WalloniaBrussels (FWO and FNRS), the Flemish Institute for Technological Research (VITO), Tekna Plasma Europe (Macon, France), AFS Entwicklungs + Vertriebs GmbH (Horgau, Germany), InnoPhysics BV (Eindhoven, The Netherlands), Benelux Process bvba (Eke, Belgium), Bruker Belgium NV/SA (Evere, Belgium), Laser 2000 Benelux CV (Vinkeveen,

Annemie Bogaerts

annemie.bogaerts@uantwerpen.be

Richard van de Sanden

M.C.M.vandeSanden@differ.nl

1 Department of Chemistry, University of Antwerp, Antwerp, Belgium

2 Dutch Institute for Fundamental Energy Research, Eindhoven, The Netherlands 
The Netherlands), Newport Spectra-Physics (Utrecht, The Netherlands), Springer Science + Business Media, Ltd. (New York, USA), Springer Verlag GmbH, (Heidelberg, Germany), and ST Instruments BV (Sliedrecht, The Netherlands). The conference was organized by Luc Van 't dack and his team from the Research Group PLASMANT of the University of Antwerp.

A total of 580 participants from 39 countries, including 205 students, attended the very successful ISPC 22. Six plenary lectures, one devoted to the Plasma Chemistry Award, and twenty topical invited lectures were presented. The programme contained in addition a total of 175 oral contributions and 344 posters presentations. The Plasma Chemistry Award, the prestigious and highest award given by the International Plasma Chemistry Society, was this year awarded to Professor Maher Boulos of the Sherbrooke University and Tekna Plasma Systems Inc. for his lifetime achievements in the field of Plasma Chemistry.

The papers in this special issue contain 4 of the plenary invited lecturer papers and 16 topical invited papers. They have gone through the full review procedure of Plasma Chemistry and Plasma Processing. They therefore give an excellent impression and cover the full scope of the ISPC 22 conference and they present the state-of-the-art of our quickly evolving field of Plasma Chemistry and Plasma Processing Science.

We would like to thank all the contributors to this special issue, as well as the editorial staff, for their support in the preparation of this special issue. We sincerely hope that you will enjoy reading the special issue, and that it will be a helpful guidance for young researchers, to become more familiar with the state-of-the-art on plasma chemistry and plasma processing science. 